\title{
On the budget of hydroxyl radicals at Schauinsland during the Schauinsland Ozone Precursor Experiment (SLOPE96)
}

\author{
Andreas Volz-Thomas and Bita Kolahgar \\ Institut für Chemie und Dynamik der Geosphäre II, Forschungszentrum Jülich, Jülich, Germany
}

\begin{abstract}
The concentration of hydroxyl radicals is estimated from the degradation of $\mathrm{NO}_{x}$ and selected volatile organic compounds (VOCs) during the transport of polluted air masses from the city of Freiburg to the Schauinsland mountain through a steep valley called "Großes Tal." The approach is based upon chemical and meteorological measurements made during the Schauinsland Ozone Precursor Experiment (SLOPE96) at two ground-based sites and aboard a small aircraft. Separation of chemistry and transport is achieved through the degradation of chemical compounds with significantly different reactivity towards $\mathrm{OH}$. The transport time of the air between the two measurements $(90 \pm 5 \mathrm{~min}$ ) and the influence of mixing with background air on the calculated $\mathrm{OH}$ concentration is quantified with the help of a dispersion experiment with $\mathrm{SF}_{6}$ and from airborne chemical measurements. The $\mathrm{OH}$ concentration $\left(7-10 \times 10^{6} \mathrm{~cm}^{-3}\right)$ is almost a factor of 2 larger than what is calculated with a chemical box model constrained by the measured trace gas concentrations and photolysis rates. The radical budget can be closed within the experimental uncertainties, when an upper limit is adopted for the photolysis of nitrous acid, in addition to the radical production from photolysis of ozone, $\mathrm{H}_{2} \mathrm{O}_{2}$, and carbonyl compounds as well as ozonolysis of unsaturated VOCs. Biogenic VOCs (i.e., isoprene, terpenes, and a number of oxidated compounds) comprise about half of the total VOC reactivity in the transported plume. The results from SLOPE96 confirm the assumptions made in the analysis of an earlier experiment conducted in 1992, when noontime $\mathrm{OH}$ concentrations of $6-8 \times 10^{6} \mathrm{~cm}^{-3}$ were derived in the presence of $\mathrm{NO}_{x}$ mixing ratios between $70 \mathrm{ppb}$ at the entrance of the valley and $15 \mathrm{ppb}$ at Schauinsland. Comparison with direct measurements from different studies qualitatively reveals the expected dependence of $[\mathrm{OH}]$ on the $\mathrm{NO}_{2}$ mixing ratio with a maximum around $1-2 \mathrm{ppb}$ of $\mathrm{NO}_{2}$.
\end{abstract}

\section{Introduction}

An important aspect of the Schauinsland Ozone Precursor Experiment (SLOPE96) campaign was to investigate the budget of hydroxyl radicals by detailed chemical and meteorological measurements in the plume of the city of Freiburg during its transport to the Schauinsland hill. The idea for SLOPE96 came from the analysis of the long-term measurements made at Schauinsland as part of the European Experiment on Transport and Transformation of Environmentally Relevant Trace Constituents in the Troposphere Over Europe (EUROTRAC) subproject Tropospheric Ozone Research (TOR) [Kley et al., 1997]. It was found that during anticyclonic conditions with weak synoptic winds, polluted air masses from the nearby city of Freiburg are channeled to Schauinsland through the valley "Großes Tal" that declines from Schauinsland to the north [e.g., Kramp and Volz-Thomas, 1997; Flocke et al., 1998]. This led to the idea of utilizing the valley as an approximation of a flow reactor for studying the chemical processes in the atmosphere. A first experiment was conducted in September 1992 with ground-based measurements made at Kappel, a small village at the entrance of the valley and at Schauinsland (for details, see Volz-Thomas et al. [this issue]).

The time-integrated average $\mathrm{OH}$ radical concentration was

Copyright 2000 by the American Geophysical Union.

Paper number 1999JD901046.

0148-0227/00/1999JD901046\$09.00 estimated from the slope of a semilogarithmic plot (according to Kramp and Volz-Thomas [1997, equation 1]) of the ratios of individual hydrocarbon concentrations, as measured at the two locations along the transport path, versus their reaction rate coefficients with $\mathrm{OH}$. The dilution coefficient was derived from the intercept.

$$
\ln \left(\frac{\left[X_{t}\right]_{t_{2}}}{\left[X_{t}\right]_{t_{1}}}\right)=-k_{\mathrm{OH}}[\overline{\mathrm{OH}}] \Delta t-\overline{k_{v}} \Delta t
$$

where $\left[X_{i}\right]_{t_{1}, t_{2}}$ are the mixing ratios of the components $X_{t}$ at the time of measurement, that is, $t_{1}$ (Kappel) and $t_{2}$ (Schauinsland), $k_{\mathrm{OH}}$ are the rate coefficients for the reaction of $X_{\imath}$ with $\mathrm{OH}, \Delta t=t_{2}-t_{1}$ is the transport time between two measuring sites, and $k_{v}$ is a first-order dilution coefficient. This simple model, which has been used in slightly modified versions in several studies [e.g., Calvert, 1976; Singh et al., 1981; Roberts et al., 1984; Rudolph and Johnen, 1990; McKeen et al., 1996; Blake et al., 1993; McKenna et al., 1995; Kramp and Volz-Thomas, 1997], requires the fulfillment of several assumptions: First of all, it is assumed that reaction with $\mathrm{OH}$ is the major removal path for the species under concern. Another essential requirement is that the same air mass is traced subsequently by measurements at two locations. Finally, production or emissions of the species during transport is assumed to be negligible, as are the concentrations in the background air with which the plume is mixed during transport between the two measurements. With the latter assumption the dilution term $k_{\nu} \Delta t$ is equivalent 
to a volumetric dilution factor, $\ln \left(V_{t_{2}} / V_{t_{1}}\right)$. This can easily be verified from (1) for an inert molecule $\left(k_{\mathrm{OH}}=0\right)$ and by substituting the concentrations $\left[X_{1}\right]_{t}$ by the total number of molecules $n_{i}$ and the volume $V_{t}$, with the condition that $n_{i}$ remains constant in the absence of chemical losses.

The OH concentrations derived in 1992 were unexpectedly large in view of the prevailing $\mathrm{NO}_{x}$ mixing ratio in the plume ( $70 \mathrm{ppb}$ at Kappel and $15 \mathrm{ppb}$ at Schauinsland). A budget analysis showed that the estimated $\mathrm{OH}$ concentrations could not be explained by primary production, thus indicating the potential for significant radical amplification during the oxidation of hydrocarbons [Kramp and Volz-Thomas, 1997]. Since biogenic VOCs other than isoprene were not measured during the experiment in 1992, it was suggested that these compounds could affect the $\mathrm{OH}$ budget by the production of $\mathrm{OH}$ and $\mathrm{HO}_{2}$ radicals during ozonolysis, as reported by many authors [e.g., Niki et al., 1987; Hatakeyama et al., 1991; Paulson and Orlando, 1996; Paulson et al., 1998; Donahue et al., 1998; Marston et al., 1998; Mihelcic et al., 1999].

Uncertainties in the $\mathrm{OH}$ concentrations estimated from the 1992 experiment were associated with the assumptions about the transport path and the transport time between the two measuring sites, as well as the possible influence of mixing of the plume with the surrounding air masses. Therefore tracer experiments with $\mathrm{SF}_{6}$ were conducted in the subsequent years (M. Möllmann-Coers et al., unpublished manuscript, 1999), which in general confirmed the assumptions about the transport path and the transport time. The aim of SLOPE96 was to repeat the experiment from 1992 with more detailed chemical and meteorological measurements, including vertical profiles at several locations and a small aircraft.

The aim of this paper is to estimate the time-integrated $\mathrm{OH}$ concentration from the degradation of selected VOCs and to investigate the validity of the necessary assumptions adopted in the approach. These include in particular the influence of mixing of the plume with background air on the estimated $\mathrm{OH}$ concentrations. The thus derived $\mathrm{OH}$ concentration is compared with results from other direct measurements and with predictions from a chemical box model constrained by the ancillary data. Finally, the budget of $\mathrm{HO}_{x}\left(\mathrm{OH}\right.$ and $\left.\mathrm{HO}_{2}\right)$ is examined in light of the primary sources and sinks, including the influence of biogenic VOCs.

\section{Results}

The scientific background and the details of SLOPE96 are described by Volz-Thomas et al. [this issue]. The campaign involved a large number of ground-based chemical and meteorological measurements, as well as vertical profiles at several locations in the valley. Measurements aboard a small aircraft were made to obtain information on the trace gas concentrations in the surrounding air masses. These included $\mathrm{O}_{3}, \mathrm{NO}_{2}$, and in situ measurements of VOCs with an Airmotec HC1010 gas chromatograph (10 $\mathrm{min}$ time resolution). The chemical measurements are described by B. Kolahgar et al. (unpublished manuscript, 1999) for the organic compounds and by Pätz et al. [this issue] for the inorganic compounds, photolysis rates, and carbonyl compounds $<C_{5}$. A dispersion experiment with $\mathrm{SF}_{6}$ was performed to verify the transport path of the air mass and to determine the transport time between the two sites, where the chemical measurements were made. The meteorological situation as well as transport and dispersion are discussed by Kalthoff et al. [this issue].
Figure 1 summarizes the trace gas concentrations obtained at the entrance of the valley (Kappel) and at Schauinsland on June 5, 1996, the only day during the entire SLOPE campaign when upvalley flow in the valley persisted for a long enough time period [Volz-Thomas et al., this issue]. The valley wind system was established at 0730 LT at Kappel [see Kalthoff et al., this issue]. At 0950 LT the Freiburg plume arrived at Kappel, as is evident by the peak mixing ratios of primary pollutants like $\mathrm{NO}_{x}$ and anthropogenic VOCs. The tracer $\left(\mathrm{SF}_{6}\right)$ arrived at the same time as the anthropogenic trace gases. Thus the $\mathrm{SF}_{6}$ maximum can be used as a marker for the air mass to be investigated. At Schauinsland the $\mathrm{SF}_{6}$ maximum occurred between 1100 and 1130 LT. The transport time of the plume between Kappel and Schauinsland as derived by fitting a Gaussian plume to the $\mathrm{SF}_{6}$ concentrations was $90 \pm 5 \mathrm{~min}$. The transport time calculated from the average surface wind velocity $\left(1.8 \mathrm{~m} \mathrm{~s}^{-1}\right)$ and the distance between the two measuring sites $(\sim 8 \mathrm{~km})$ was somewhat smaller, about $80 \mathrm{~min}$. In contrast, the peak $\mathrm{NO}_{x}$ and VOC mixing ratios occurred at Schauinsland at $1300 \mathrm{LT}$, about $200 \mathrm{~min}$ later than in Kappel. However, at this time the larger fraction of the air masses observed at Schauinsland was not advected through the valley anymore, as the wind regime had changed to westerly flow around $2400 \mathrm{LT}$ [see Kalthoff et al., this issue; Fiedler et al., this issue]. During the arrival of $\mathrm{SF}_{6}$ peak, advection to Schauinsland was still predominated by the valley wind system [Fiedler et al., this issue].

The analysis for $\mathrm{OH}$ according to (1) is shown in Figure 2. The ratios of the mixing ratios of $\mathrm{NO}_{x}$ and several hydrocarbons as measured at $t_{1}$ in Kappel and at $t_{2}$ at Schauinsland (see Table 1) are plotted as a function of the respective rate coefficients in a semilogarithmic diagram. The analysis is made for transport times of 80,100 , and $120 \mathrm{~min}$, the increment of 20 min being determined by the analytical cycle of the VOC measurements with the Airmotec gas chromatographs (GCs) (see B. Kolahgar et al., unpublished manuscript, 1999).

Only those compounds are included in the analysis that are unambiguously identified in the chromatograms and are observed at mixing ratios well above the detection limit at both sites. Compounds $<C_{5}$ are excluded because they are not accurately quantified with our Airmotec GCs. The two custom made GCs, which accurately measured the small VOCs, and the gas chromatography/mass spectroscopy (GC/MS) samples have analytical cycles of about 1.5 and 3.5 hours, respectively, too long for the $\mathrm{OH}$ analysis. Compounds with significant biogenic sources are excluded, since the assumption of negligible emissions between the two measuring sites is not fulfilled for such compounds. Anthropogenic emissions in the valley are rather unimportant compared to the advection of pollutants from Freiburg because of the sparse population and due to the fact that the public road ends in the valley [Volz-Thomas et al., this issue].

Another requirement is that the rate coefficients for reaction with $\mathrm{OH}$ must be sufficiently well known from laboratory experiments. For this reason, 3-methyl hexane, albeit being measured with high precision at both sites, had to be excluded from the analysis. The rate coefficients used in Figure 2 were adopted from Atkinson [1994] for the VOCs and from Donahue et al. [1997] for $\mathrm{NO}_{2}$. As m-xylene and p-xylene react with $\mathrm{OH}$ at different rates and are not separated by the Airmotec GCs, the effective rate coefficient for the sum of $\mathrm{m}$ - and p-xylene was calculated from the individual rate coefficients and the ratio of these compounds as determined from the 
Kappel
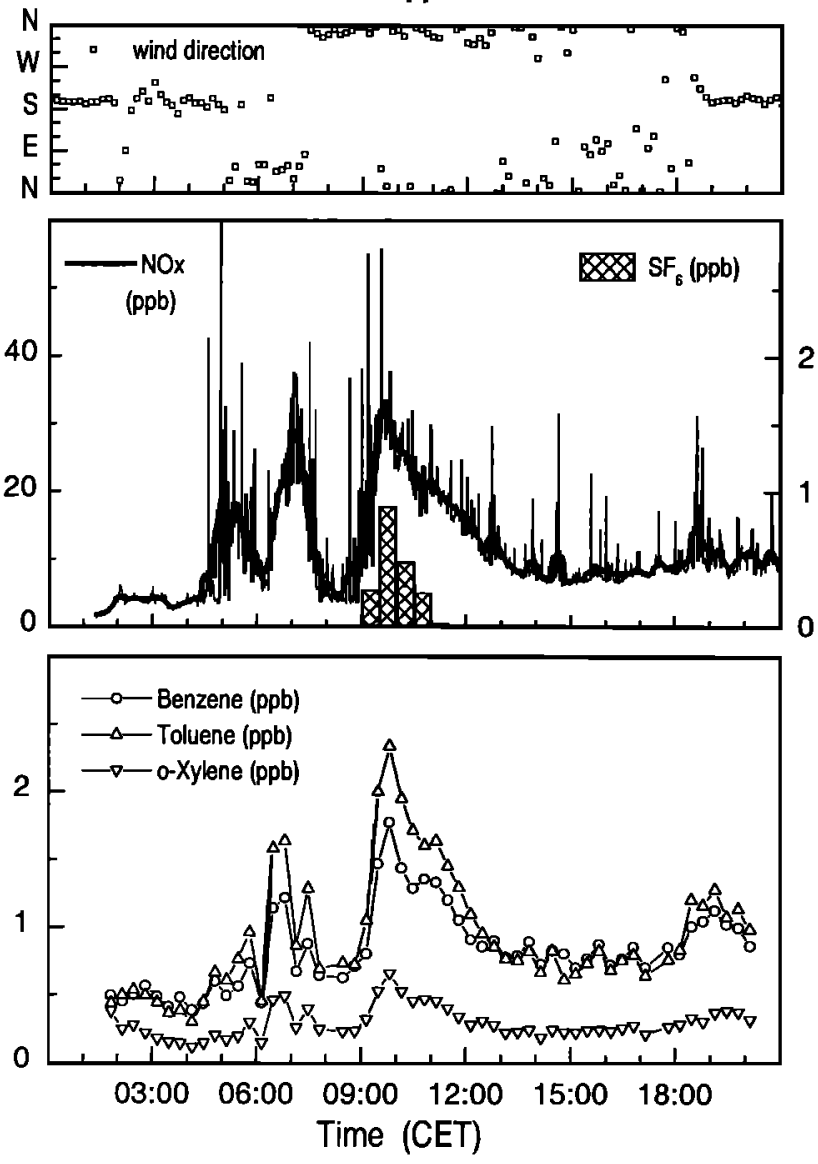

Schauinsland
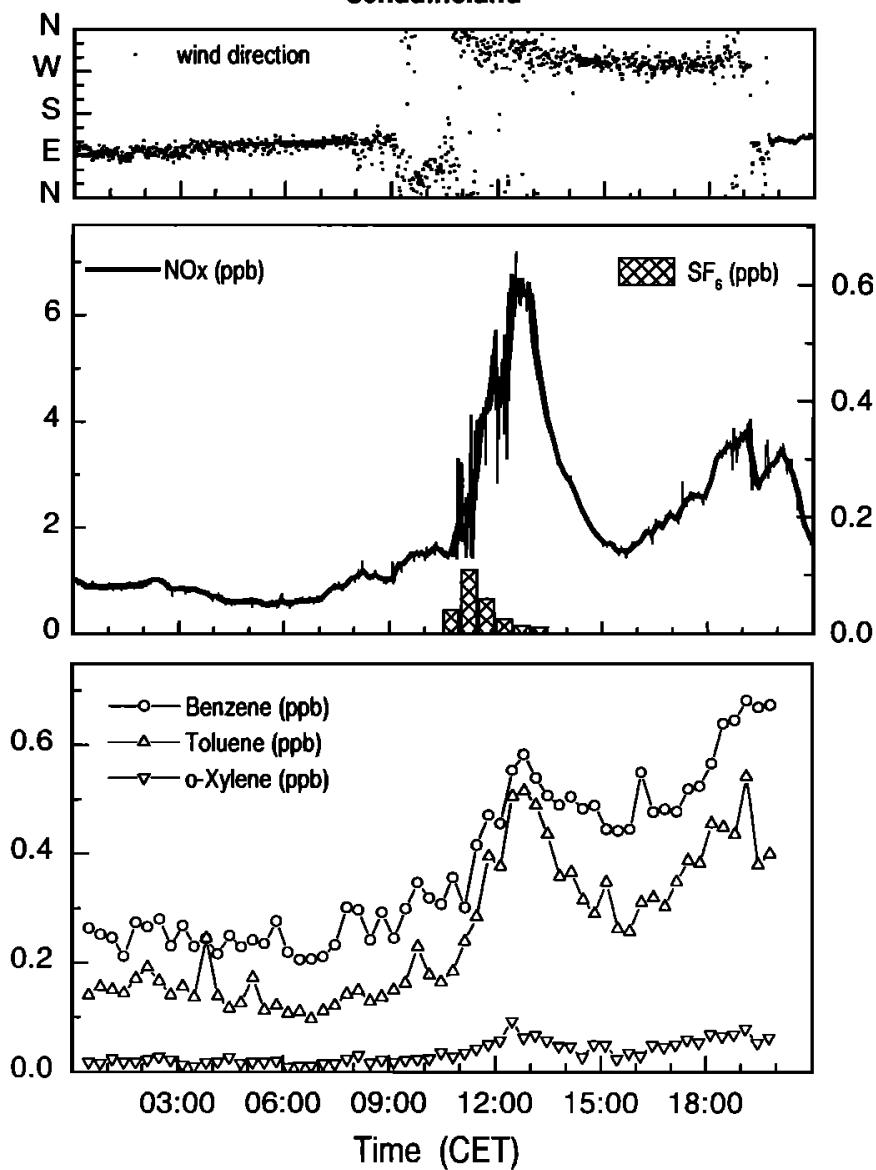

Figure 1. Diurnal variation of wind direction, $\mathrm{NO}_{x}, \mathrm{SF}_{6}$, and selected VOCs at (left) Kappel and (right) Schauinsland on June 5, 1996. The thick lines are 10 min moving averages of the $\mathrm{NO}_{x}$ data.

GC/MS measurements at Kappel and Schauinsland ([pxylene $] /[$ m-xylene $]=2$ (B. Kolahgar et al., unpublished manuscript, 1999).

$\mathrm{NO}_{x}$ was used in the analysis instead of $\mathrm{NO}_{2}$ because changes in the $\mathrm{O}_{3}$ concentration or in the photolysis frequency of $\mathrm{NO}_{2}$ during transport would lead to changes in $\mathrm{NO}_{2}$ according to the photostationary state relation (PSS) [Leighton, 1961], in addition to changes due to reaction of $\mathrm{NO}_{2}$ with $\mathrm{OH}$. The effective rate coefficient for the reaction of $\mathrm{NO}_{x}$ with $\mathrm{OH}$ was calculated by multiplying the rate coefficient for the reaction of $\mathrm{NO}_{2}$ with $\mathrm{OH}$ with the average $\mathrm{NO}_{2} / \mathrm{NO}_{x}$ ratio of 0.7 , as determined from the measurements at Kappel and Schauinsland. Other than the VOCs in Figure 2, $\mathrm{NO}_{2}$ is subject to dry deposition [e.g., Munger et al., 1996]. With a relatively high value for the deposition velocity of $0.5 \mathrm{~cm} \mathrm{~s}^{-1}$ and a lower limit for the mixing height of $200-300 \mathrm{~m}$ [Kalthoff et al., this issue], $\mathrm{NO}_{2}$ deposition constitutes a first-order loss of $<2.5 \times 10^{-5}$ $\mathrm{s}^{-1}$. The data in Figure 2 for $\mathrm{NO}_{x}$ are thus shown with and without including this estimate for deposition (solid and open triangles, respectively).

According to (1) the average $\mathrm{OH}$ concentration is calculated from the slope of a linear regression with the corresponding transport time $\left(\Delta t=t_{2}-t_{1}\right)$. The dilution rate coefficient is derived from the intercept. The dotted lines in Figure 2 are linear regressions through all compounds shown in the plot, and the solid lines are fits to those compounds (shown as solid squares) for which the intersystem comparability was found to be better than $10 \%$ (see B. Kolahgar et al., unpublished manuscript, 1999). Table 2 summarizes the average OH concentrations, the dilution coefficients, and the corresponding dilution factors, as well as the correlation coefficients of the regression. Over the range of possible transport times, $[\mathrm{OH}]$ varies by approximately a factor of 2 . While the selection of higherquality compounds has no significant influence on the $\mathrm{OH}$ concentration or the dilution factor, the correlation coefficients are much larger. The somewhat higher values of $R^{2}$ for 80 and $100 \mathrm{~min}$ are in line with the transport time $(90 \pm 5 \mathrm{~min})$ from $\mathrm{SF}_{6}$. The resulting $\mathrm{OH}$ concentration is $10-15 \times 10^{6}$ $\mathrm{cm}^{-3}$, and the first-order dilution coefficients $\left(2.6-3.6 \times 10^{-4}\right.$ $\mathrm{s}^{-1}$ ) are equivalent to a volumetric dilution factor of $V_{t 2} / V_{t 1} \approx$ 5 .

The large deviation for $\mathbf{n}$-octane for $80 \mathrm{~min}$ is caused by a somewhat high value measured at Schauinsland. The reason for the significant deviation of 2-methylbutane in all three panels is likely due to the measurement at Kappel. The estimate for $\mathrm{NO}_{x}$ with deposition is in better agreement with the rest of the compounds, although we should like to note that neglecting deposition of $\mathrm{NO}_{2}$ changes the estimate for [OH] by less than $0.3 \times 10^{6} \mathrm{~cm}^{-3}$.

Whereas the statistical errors of the measurements and the rate coefficients $(<20 \%)$ should be reflected in the errors of the slopes of the regression lines, systematic errors in the estimated $\mathrm{OH}$ concentration may arise from the assumptions of the approach. The dilution factor of 5 derived from the 

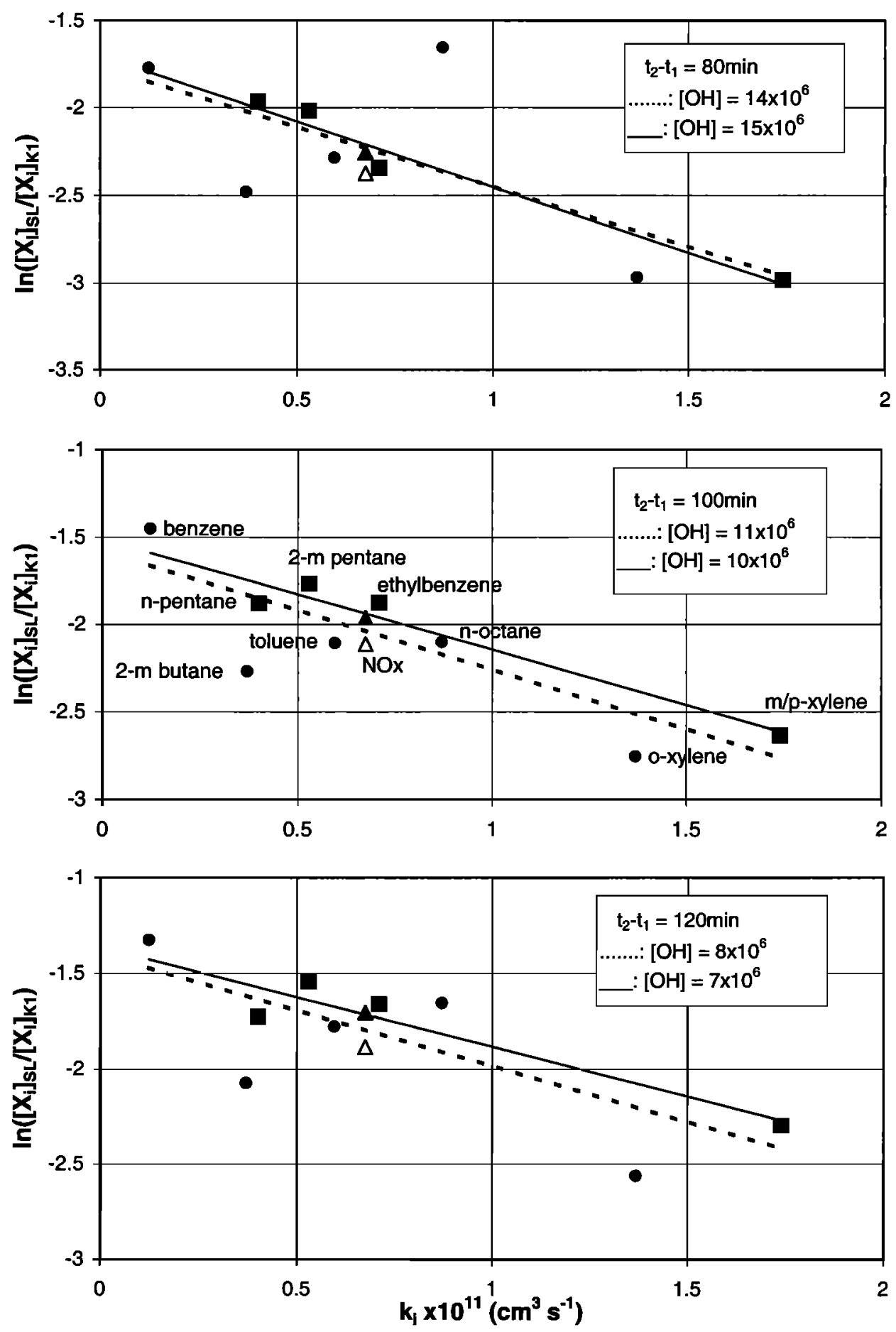

Figure 2. Semilogarithmic plots of VOC ratios as measured with the two Airmotec GCs at Kappel (0950 LT; $\left.X_{K}\right)$ and at Schauinsland $\left(1110,1130\right.$, and $\left.1150 \mathrm{LT} ; X_{S}\right)$ versus their rate coefficients for reaction with $\mathrm{OH}$ $\left(k_{i}\right) . \mathrm{NO}_{x}$ is shown with (solid triangle) and without (open triangle) correction for losses by dry deposition (with $v_{D}=0.5 \mathrm{~cm} \mathrm{~s}^{-1}$ and a scale height of $200 \mathrm{~m}$ ). The dotted lines are linear fits through all data, and the solid lines are obtained by including only compounds which were measured with a comparability of $10 \%$ (solid squares and triangle).

intercept of the regression line for 80 and $100 \mathrm{~min}$ (Table 2) is a factor of 2 lower than that obtained from the $\mathrm{SF}_{6}$ experiment $\left(V_{t_{2}} / V_{t_{1}}=10\right.$ [Kalthoff et al., this issue]. This difference can be explained either by emissions of the compounds between the two measuring sites or by admixture of background air that contains significant concentrations of the respective com- pounds. Local emissions and the background of $\mathrm{SF}_{6}(4 \mathrm{ppt}$ [Geller et al., 1997]) are negligibly small compared to the observed $\mathrm{SF}_{6}$ mixing ratios in the plume $(>1 \mathrm{ppb})$. The influence of mixing can be investigated from independent information about the concentrations of the VOCs and $\mathrm{NO}_{x}$ in the background air above the valley. This information can be obtained 
Table 1. Mixing Ratios of $\mathrm{NO}_{x}$ and Selected VOCs Measured at the Surface Sites and Aboard the Aircraft Above Kappel as Used for Estimation of the $\mathbf{O H}$ Concentration

\begin{tabular}{lccc}
\hline \multicolumn{1}{c}{ Compound } & $\begin{array}{c}t_{1}, \text { Kappel, } \\
\text { Surface, ppt }\end{array}$ & $\begin{array}{c}t_{1}, \text { Kappel, } \\
1200 \mathrm{~m}, \mathrm{ppt}\end{array}$ & $\begin{array}{c}t_{2}, \text { Schauinsland, } \\
\text { ppt }\end{array}$ \\
\hline 2-Methylbutane & 3,321 & 223 & 343 \\
n-Pentane & 2,111 & 240 & 322 \\
2-Methylpentane & 1,495 & 120 & 255 \\
Benzene & 1,775 & 206 & 415 \\
Toluene & 2,339 & 214 & 284 \\
n-Octane & 131 & 8 & 16 \\
Ethylbenzene & 458 & 33 & 70 \\
m/p-Xylene & 1,283 & 60 & 92 \\
o-Xylene & 661 & 96 & 42 \\
NO & 29,000 & 3,000 & 3,700 \\
\hline
\end{tabular}

either from the nighttime concentrations measured at Schauinsland, as it was done by Kramp and Volz-Thomas [1997], or from aircraft measurements. During the 1992 experiment, aircraft measurements were not available. The nighttime concentrations at Schauinsland were less than $10 \%$ of the concentrations at Schauinsland during arrival of the plume and were neglected in the analysis. Because of the lower $\mathrm{NO}_{x}$ and VOC concentrations within the plume during SLOPE96, the nighttime concentrations at Schauinsland were, on average, $35 \%$ of the concentrations measured during the arrival of the plume at 1130 LT. The concentrations measured by the aircraft at 0950 LT in the background air above Kappel (see Table 1) were a factor of 2 higher than the nighttime concentrations measured at Schauinsland. Thus the influence of mixing with air from aloft was more pronounced during SLOPE96 than during the 1992 experiment.

With the information about the chemical composition of the background air and the dilution factor, (1) can be expanded, using a simple mixing scheme:

$$
\left[X_{t}\right]_{S}=\left(\left[X_{t}\right]_{K} f+\left[X_{t}\right]_{R} f^{\prime}\right) \exp \left(-k_{\mathrm{OH}}[\overline{\mathrm{OH}}] \Delta t\right)
$$

or

$$
\ln \left(\frac{\left[X_{t}\right]_{S}}{f\left[X_{t}\right]_{K}+f^{\prime}\left[X_{\mathrm{t}}\right]_{B}}\right)=-k_{\mathrm{OH}}[\overline{\mathrm{OH}}] \Delta t
$$

where $\left[X_{t}\right]_{S},\left[X_{t}\right]_{K}$, and $\left[X_{t}\right]_{B}$ are the mixing ratios as measured at Schauinsland $\left(t_{2}\right)$, at Kappel $\left(t_{1}\right)$, and above Kappel $\left(t_{1}\right)$, as listed in Table $1, \Delta t=100 \mathrm{~min}$ is the transport time between Kappel $\left(t_{1}\right)$ and Schauinsland $\left(t_{2}\right)$, and $f=V_{K} / V_{S}=$
0.1 is the reciprocal dilution factor. Both quantities are taken from the $\mathrm{SF}_{6}$ experiment. Here $f^{\prime}=(1-f)$ is the fraction at which the background air is admixed to the plume. Equation (2) assumes instantaneous mixing. The results of the tracer experiment indeed show that mixing is completed during the first hour of transport.

The $\mathrm{NO}_{x}$ mixing ratio in the background air above Kappel was calculated with the photostationary state relation [Leighton, 1961] from the mixing ratios of $\mathrm{O}_{3}$ and $\mathrm{NO}_{2}$ measured aboard the aircraft and the $J_{\mathrm{NO}_{2}}$ data from Schauinsland.

$$
\left[\mathrm{NO}_{\mathbf{x}}\right]=\left(\frac{J \mathrm{NO}_{2}}{\left[\mathrm{O}_{3}\right] k_{\mathrm{O}_{3}, \mathrm{NO}}}+1\right)\left[\mathrm{NO}_{2}\right]
$$

Neglection of the oxidation of NO by peroxy radicals in (3) leads to a slight $(10 \%)$ overestimation of $\left[\mathrm{NO}_{x}\right]_{B}$.

The results of the analysis according to (2) are shown in Figure 3 for a transport time of $100 \mathrm{~min}$. When including all VOCs in the analysis, the OH concentration is $10 \pm 4 \times 10^{6}$ $\mathrm{cm}^{-3}\left(R^{2}=0.52\right)$, similar to that obtained from (1). The slope of the regression line is significantly effected by o-xylene, for which a significant memory was found in the airborne GC (see B. Kolahgar et al., unpublished manuscript, 1999). If the analysis is constrained to $\mathrm{NO}_{x}$ and those VOCs that were measured with all three Airmotec GCs with sufficient comparability (squares), the slope of the regression line is $30 \%$ smaller, yielding $[\mathrm{OH}]=7 \pm 4 \times 10^{6} \mathrm{~cm}^{-3}\left(R^{2}=0.62\right)$. The smaller correlation coefficients are due to the fact that measurement errors of three GCs enter in the analysis. As before, exclusion of compounds that are measured with a lower precision improves the correlation. The same analysis for $\Delta t=80$ $\min$ (not shown) gives $[\mathrm{OH}]=10 \pm 3 \times 10^{6} \mathrm{~cm}^{-3}\left(R^{2}=\right.$ $0.83)$.

Figure 4 shows the mass balance of the trace gases at Schauinsland. The concentrations $\left[X_{t}\right]_{S}$, are calculated with (2) from the concentrations measured at Kappel (0950 LT) and in the air above Kappel (0950 LT), after being aged during transport to Schauinsland. The thus calculated mixing ratios are compared to those measured at $1130 \mathrm{LT}$ at Schauinsland $\left(\left[X_{i}\right]_{s}\right)$, which are set equal to $100 \%$. With an average $\mathrm{OH}$ concentration of $7 \times 10^{6} \mathrm{~cm}^{-3}$ the mass balance of the compounds shown with squares in Figure 3 can be closed to $95 \%$. The contribution of the surface air as measured at Kappel is $50-60 \%$. The residual deviations from $100 \%$ may be due to errors in the GC analysis or could be indicative of minor emissions in the valley. As stated before, emissions of the compounds between Kappel and Schauinsland would lead to an underestimation of the real $\mathrm{OH}$ concentration. In conclu-

\begin{tabular}{|c|c|c|c|c|c|c|}
\hline$\Delta t, \min$ & $t_{1}, \mathrm{CET}$ & $t_{2}, \mathrm{CET}$ & $\underset{\mathrm{cm}^{-3}}{[\mathrm{OH}] \times 10^{-6}}$ & $k_{\nu} \times \mathrm{s}^{-1}{ }^{-10^{4}}$ & $V_{t 2} / V_{t 1}$ & $R^{2}$ \\
\hline & & & All Data & & & \\
\hline 80 & 0950 & 1110 & $14 \pm 5$ & $3.7 \pm 0.4$ & 5.8 & 0.55 \\
\hline 100 & 0950 & 1130 & $11 \pm 3$ & $2.6 \pm 0.2$ & 4.8 & 0.71 \\
\hline 120 & 0950 & 1150 & $8 \pm 3$ & $1.9 \pm 0.2$ & 3.9 & 0.59 \\
\hline \multicolumn{7}{|c|}{ Compounds Shown as Squares Only } \\
\hline 80 & 0950 & 1110 & $15 \pm 2$ & $3.6 \pm 0.4$ & 5.5 & 0.97 \\
\hline 100 & 0950 & 1130 & $10 \pm 2$ & $2.5 \pm 0.2$ & 4.5 & 0.94 \\
\hline 120 & 0950 & 1150 & $7 \pm 2$ & $1.9 \pm 0.2$ & 3.9 & 0.88 \\
\hline
\end{tabular}

Table 2. Average $\mathrm{OH}$ Concentration, Dilution Rate Coefficient, Volumetric Dilution Factor, and Correlation Coefficient Obtained From the Linear Regressions in Figure 2 for Different Transport Times

CET, central European time. 


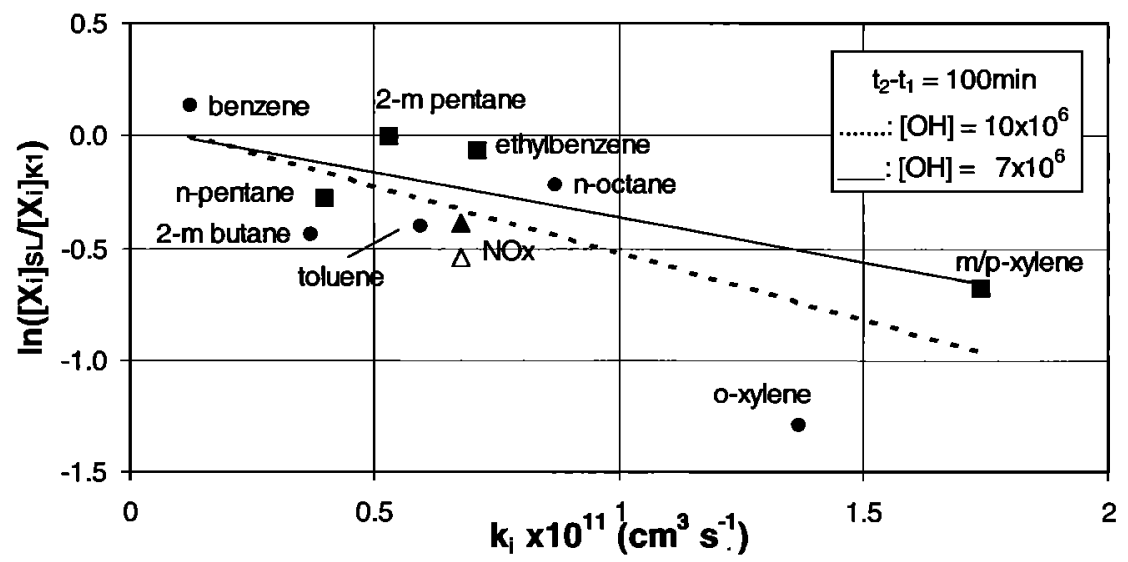

Figure 3. Semilogarithmic plot of hydrocarbon ratios measured at $0950 \mathrm{LT}$ at Kappel and at $1130 \mathrm{LT}$ at Schauinsland according to equation (2) versus the respective $\mathrm{OH}$ rate coefficients $\left(k_{t}\right)$. Background concentrations were measured at 0950 LT above Kappel $(1230 \mathrm{~m})$. Symbols and lines are as in Figure 2.

sion, when using all the available experimental information in a simple model that allows mixing of the air measured at Kappel with air from aloft, an average $\mathrm{OH}$ concentration of $7-10 \times 10^{6} \mathrm{~cm}^{-3}$ is derived for the time interval $0950-1130 \mathrm{LT}$ on June 5, 1996.

\section{Discussion}

Several authors reported on the estimation of $\mathrm{OH}$ concentrations from the degradation of hydrocarbons [e.g., Calvert, 1976; Singh et al., 1981; Roberts et al., 1984; Satsumabayashi et al., 1992; Blake et al., 1993; McKenna et al., 1995]. When taking into account the different atmospheric conditions and that some of the estimates were diurnal averages, the estimated $\mathrm{OH}$ concentrations are comparable to those obtained in this study. The highest $\mathrm{OH}$ concentrations $\left(20 \times 10^{6} \mathrm{~cm}^{-3}\right)$ were derived from the decay of olefinic hydrocarbons during transport from a highly polluted coastal site in Japan to the inland in the presence of about $50 \mathrm{ppb} \mathrm{NO}_{2}$ [Satsumabayashi et al., 1992].

In many of the investigations, uncertainties are associated with the estimation of the transport time of the air masses from the source region to the measuring site. Large errors can also arise from the assumed emission patterns, when measurements

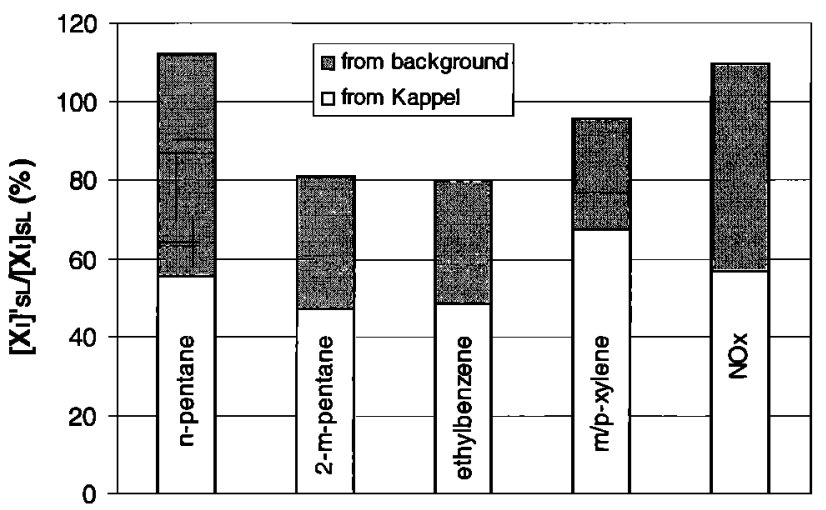

Figure 4. Mass balance between Kappel and Schauinsland calculated according to equation (2) with an average $\mathrm{OH}$ concentration of $7 \times 10^{6} \mathrm{~cm}^{-3}$ and a dilution factor $\left(V_{t 2} / V_{t 1}\right)$ of 10. The measured concentrations at Schauinsland are set equal to $100 \%$. from only one location are used. Finally, emissions during transport and admixture of significant background concentrations constitute a large source of uncertainty [McKeen et al., 1996; McKenna, 1997; Schmitt and Volz-Thomas, 1997; Ehhalt et al., 1998]. The effect of mixing was often assumed to cancel by using hydrocarbon ratios. McKeen et al. [1996] compared results from a three-dimensional model with the hydrocarbon measurements made during the Pacific Exploratory MissionWest A (PEM-West A). The model-predicted photochemical decay (with a diurnally averaged $\mathrm{OH}$ concentration of $2 \times 10^{6}$ $\mathrm{cm}^{-3}$ ) was reproduced by the measured hydrocarbon ratios only when an appropriate background was subtracted from the reference compound.

In SLOPE the VOC measurements were made at two locations within a relatively short distance. Therefore no assumptions about the VOC concentrations in the source region were necessary. Transport time, dilution factor, and chemical composition of the background air were derived from independent measurements. Most important, the narrow valley which channels the plume from Kappel to Schauinsland greatly reduces the effect of dilution processes. As a consequence, the air mass measured at Schauinsland contains more chemical information of the air mass measured at Kappel. Last but not least, anthropogenic sources in the valley between Kappel and Schauinsland are rather small, as is confirmed by $\mathrm{CO} / \mathrm{SF}_{6}$ ratios (M. Möllmann-Coers et al., unpublished manuscript, 1999). The ideal nature of the measurement site and the comprehensive set of measurements made during SLOPE96 give a relatively high level of confidence in the $\mathrm{OH}$ concentration obtained.

Unfortunately, the meteorological situation on June 5, 1996, was less favorable than during the previous experiment on September 17, 1992, when the valley wind system persisted until 1600 LT and transported extremely polluted air to Schauinsland [Kramp and Volz-Thomas, 1997]. Table 3 shows that during SLOPE96 the estimate of $\Delta t$ from the $\mathrm{SF}_{6}$ experiment is in good agreement with that from wind speed, whereas the $\mathrm{NO}_{x}$ peak occurred much later (see above). During the 1992 experiment, however, the arrival of the $\mathrm{NO}_{x}$ plume at Schauinsland was in good agreement with the transport time calculated from wind speed $(130 \mathrm{~min})$. The tracer experiments performed in SLOPE96 thus confirm the estimate of the transport time in 1992.

The dilution factors derived from the intercept of the re- 
Table 3. Different Estimates for the Transport Time Between Kappel and Schauinsland During SLOPE96 and 1992

\begin{tabular}{lcc}
\hline \multicolumn{1}{c}{ Method } & $\Delta t$, min & $\Delta t$, min \\
SLOPE96 & SLOPE92 \\
\hline Wind speed and distance & 80 & 130 \\
SF $_{6}$ experiment & $90 \pm 5$ & not available \\
Time lag between $\mathrm{NO}_{x}$ peaks & 200 & $120-180$ \\
From $R^{2}$ of regression & $80-100$ & 150 and 180 \\
Used for OH estimation & 80 and 100 & 150 and 180 \\
\hline
\end{tabular}

${ }^{a}$ Kramp and Volz-Thomas [1997].

gression line during the 1992 experiment are a factor of 2 lower than that calculated during SLOPE96. The likely reason for this difference is the difference in meteorological conditions between the two experiments, such as the mixed layer growth. This assumption is supported by the fact that in 1992 the concentrations in the background air, as measured during the early morning hours at Schauinsland, were approximately an order of magnitude smaller than those found at Schauinsland after the onset of the upvalley flow [Kramp and Volz-Thomas, 1997]. Owing to the high concentrations in the transported plume, the influence of mixing on the estimated $\mathrm{OH}$ concentrations during the 1992 experiment was of much lesser importance than in 1996.

\subsection{Comparison With Direct Observations}

In Figure 5 the $\mathrm{OH}$ concentrations derived from SLOPE96 and in 1992 are compared with direct measurements of $\mathrm{OH}$ from two field campaigns in 1993 and 1994 at Fritz Peak,
Colorado [Eisele et al., 1994; Mount and Williams, 1997], measurements made in 1984 at Schauinsland [Platt et al., 1988] and from the Photochemistry of Plant-Emitted Compounds and OH Radicals in Northeastern Germany (POPCORN) campaign 1994 in northeast Germany [Holland et al., 1998; Brandenburger et al., 1998; Rohrer et al., 1998]. In order to put the data into perspective, $[\mathrm{OH}]$ is plotted as a function of the prevailing $\mathrm{NO}_{2}$ concentration, and the data are selected for similar values of the $\mathrm{OH}$ production rate from ozone photolysis. The values for $J_{\mathrm{O} 1 D}$ range from 2.2 to $3 \times 10^{-5} \mathrm{~s}^{-1}$, the $\mathrm{O}_{3}$ mixing ratios range from 50 to $70 \mathrm{ppb}$, and the $\mathrm{H}_{2} \mathrm{O}$ mixing ratios range from 1 to $1.5 \%$. The lower $\mathrm{H}_{2} \mathrm{O}$ concentrations at the mountain sites are roughly compensated by the larger values for $J_{\mathbf{O} 1 D}$.

Qualitatively, the data exhibit the expected dependence on the $\mathrm{NO}_{2}$ mixing ratios with maximum concentrations occurring at mixing ratios around $1-2 \mathrm{ppb}$, which was first pointed out by Hameed et al. [1979] and Logan et al. [1981]. The enhanced recycling of $\mathrm{HO}_{2}$ by reaction with $\mathrm{NO}$ serves to increase $[\mathrm{OH}]$ with increasing $\left[\mathrm{NO}_{x}\right]$ until the increasing influence of $\mathrm{OH}$ losses by reaction with $\mathrm{NO}_{2}$ serve to reduce [OH] [e.g., Eisele et al., 1994, 1997]. The earlier data from Fritz Peak seem to give somewhat lower $\mathrm{OH}$ concentrations than the other data sets. The data from SLOPE96 and from 1992 [Kramp and Volz-Thomas, 1997] qualitatively exhibit the predicted falloff in the high $\mathrm{NO}_{x}$ regime.

Figure 5 also shows the results of photochemical model simulations made for the conditions of SLOPE96 with the chemical box model EURO-RADM [Stockwell and Kley, 1994], which is based upon the Second Generation Regional Acid Deposition Model (RADM2) chemistry [Stockwell et al., 1990]

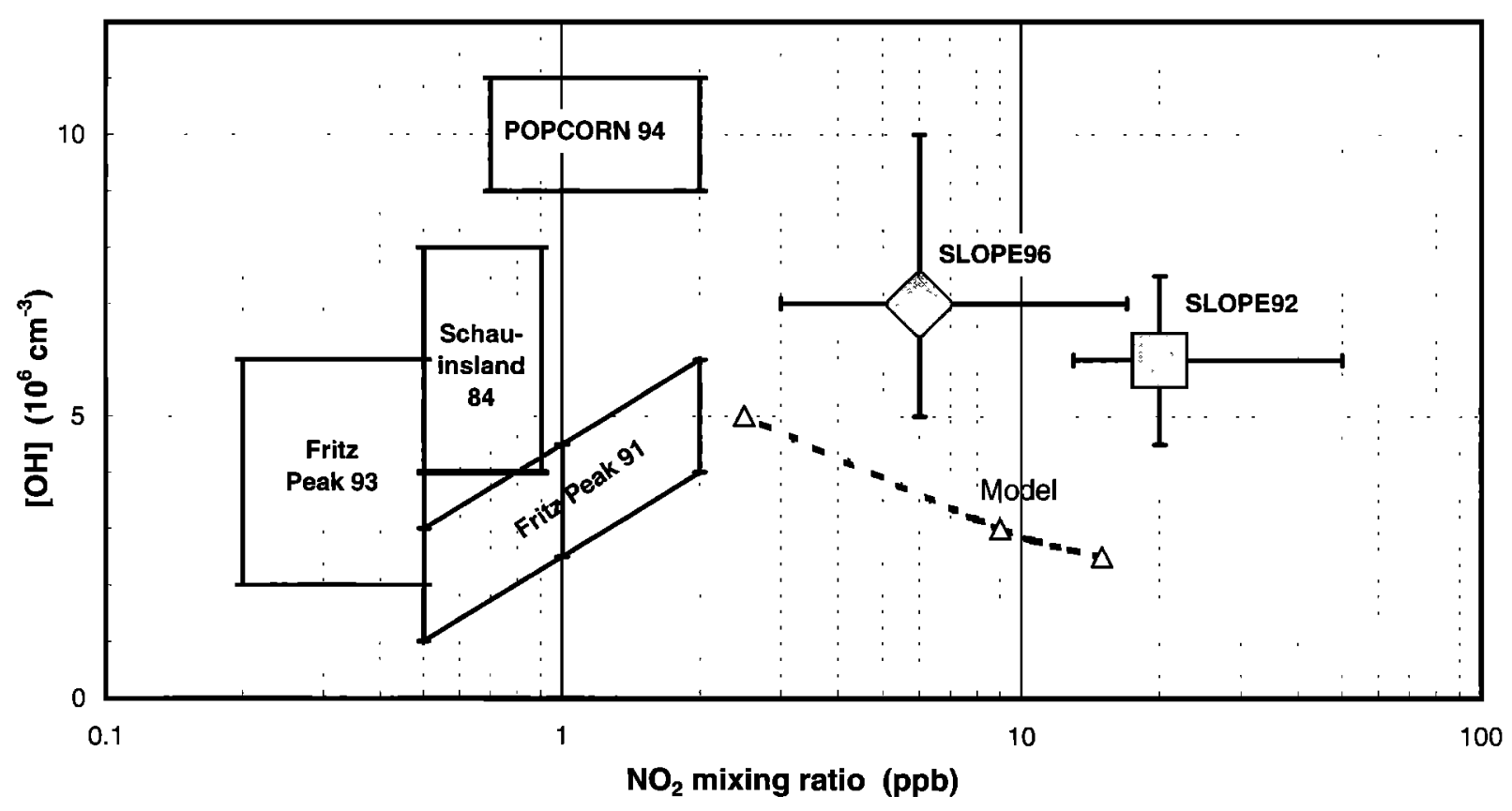

Figure 5. Comparison of the OH concentrations determined from SLOPE96 (this paper) and SLOPE92 [Kramp and Volz-Thomas, 1997] with direct spectroscopic measurements made at different locations as a function of the prevailing $\mathrm{NO}_{2}$ mixing ratio: Fritz Peak 91 [Eisele et al., 1994]; Fritz Peak 93 [Mount et al., 1997]; Schauinsland 84 [Platt et al., 1988]; POPCORN 94 [Brandenburger et al., 1998; Holland et al., 1998; Rohrer et al., 1998] (data selection for maximum $J_{\mathrm{O} 1 D}$ ). The dashed line shows the results of simulations with the photochemical box model EURO-RADM that was constrained by the ancillary measurements made during SLOPE96 (see text). 
Table 4. OH Concentrations Calculated With the Chemical Box Model EURO-RADM, Initialized With Parameters as Measured at Kappel and at Schauinsland

\begin{tabular}{|c|c|c|c|c|}
\hline & $\begin{array}{l}\text { Case } 1 \\
\text { Kappel }\end{array}$ & $\begin{array}{c}\text { Case } 2 \\
\text { Kappel } \\
\text { With } \\
\text { HONO }\end{array}$ & $\begin{array}{c}\text { Case } 3 \\
70 \% \\
\text { Kappel }\end{array}$ & $\begin{array}{c}\text { Case } 4 \\
\text { Schauinsland }\end{array}$ \\
\hline Time, CET & 1020 & 1020 & 1020 & 1200 \\
\hline $\mathrm{NO}_{2}, \mathrm{ppb}$ & 15 & 15 & 9 & 2.5 \\
\hline $\mathrm{VOC} \mathrm{NO}_{x}, \mathrm{ppb} \mathrm{C} / \mathrm{ppb}$ & 7 & 7 & 7 & 14 \\
\hline HONO, ppb & 0 & 1 & 1 & 0 \\
\hline$[\mathrm{OH}] \times 10^{-6}, \mathrm{~cm}^{-3}$ & 2 & 2.5 & 3 & 5 \\
\hline
\end{tabular}

but includes more details for several chemical species, in particular organic nitrates. For our simulations the rate coefficient in the model for the reaction of $\mathrm{NO}_{2}$ with $\mathrm{OH}$ was updated according to Donahue et al. [1997]. The rate coefficient for the reaction of $\mathrm{HO}_{2}$ with $\mathrm{NO}$ was revised to $9.7 \times 10^{-12} \mathrm{~cm}^{3} \mathrm{~s}^{-1}$ based on the new measurements made by Bohn and Zetsch [1997]. The photolysis rates were set to the values measured at Schauinsland [see Pätz et al., this issue].

Several model simulations were performed with initializations for the chemical parameters adopted from the measurements made on June 5 in the Freiburg plume at 0950 LT at Kappel (cases 1-3, Table 4) and at 1130 LT at Schauinsland (case 4 , Table 4$)$. The VOC concentrations $\left(C_{2}-C_{15}\right)$ were assimilated from all available measurements, that is, from two in situ GCs at each site and from the samples analyzed by GC/MS (see B. Kolahgar et al., unpublished manuscript, 1999). Averages were formed for those compounds which were measured by more than one instrument. The $>C_{5}$ VOCs were lumped on the basis of similarities in functional groups and reactivity. The average $\mathrm{OH}$ rate coefficient of each group $\left(\bar{k}_{\mathrm{OH}}\right)$ was calculated from the relative contributions of the individual compounds to the group:

$$
\bar{k}_{\mathrm{OH}}=\frac{\Sigma k_{\mathrm{OH}_{l}}\left[\mathrm{VOC}_{t}\right]}{\Sigma\left[\mathrm{VOC}_{t}\right]}
$$

The different scenarios are listed in Table 4 . In cases 1 and 2 the model was initialized with the trace gas concentrations measured at Kappel, case 4 was initialized with the data from Schauinsland, and case 3 represents a mix in between. The $\mathrm{OH}$ concentrations calculated by the model range from $2 \times 10^{6}$ $\mathrm{cm}^{-3}$ (conditions at Kappel without HONO) to $5 \times 10^{6} \mathrm{~cm}^{-3}$ for the conditions at Schauinsland around noontime.

Whereas the model simulations exhibit a similar dependence of $[\mathrm{OH}]$ on $\mathrm{NO}_{2}$ as the measurements (Figure 5), the absolute values of $[\mathrm{OH}]$ are approximately a factor of 2 smaller. This result is potentially important for ozone predictions made with models based upon RADM, as the photochemical ozone formation rate in the model shows a quite similar dependence on $\mathrm{NO}_{x}$ as $[\mathrm{OH}]$. A likely reason for the underprediction of $\mathrm{OH}$ by the model is the inadequate treatment of ozonolysis. More detailed modeling is necessary in order to see if the higher $\mathrm{OH}$ concentrations can be adequately simulated when ozonolysis and photolysis of higher carbonyl compounds is correctly included in the model or if there is something fundamental missing in our understanding of the photochemistry in the high- $\mathrm{NO}_{x}$ regime.

Comparison of cases 1 and 2 shows the potential influence of nitrous acid (HONO) on the $\mathrm{OH}$ concentrations. HONO is thought to be an important source of $\mathrm{OH}$ in polluted environment [e.g., Kessler and Platt, 1984]. Harrison et al. [1996] report on $\mathrm{OH}$ production rates from the photolysis of HONO which, at the highest HONO concentrations observed during daytime (2 ppb), were more than 10 times larger than those from the photolysis of ozone. In our simulation, HONO was initialized as $5 \%$ of the $\mathrm{NO}_{x}$ concentration. This fraction was reported by Kessler and Platt [1984] from concurrent measurements of $\mathrm{HONO}$ and $\mathrm{NO}_{x}$ in vehicle exhaust and in the vicinity of strong anthropogenic sources. For the conditions during SLOPE96 the photolysis lifetime of HONO was about $10 \mathrm{~min}$, as calculated from the photolysis frequency measured at Schauinsland (1-2 $\times 10^{-3} \mathrm{~s}^{-1}$ [Pätz et al., this issue]). Thus $\mathrm{OH}$ production from HONO photolysis is most important during the first 10-20 min of transport to Schauinsland.

Additional model runs (not shown) with the previously accepted rate coefficient for the reaction of $\mathrm{NO}_{2}$ with $\mathrm{OH}$ gave 10-30\% lower $\mathrm{OH}$ concentrations. For the Schauinsland mix the results are similar to those obtained by Kohlmann et al. [1999], who found about $15 \%$ larger $\mathrm{OH}$ concentrations with the new rate coefficient for simulations of rural air. The model studies for the Kappel mix highlight the particular importance of this recent finding for the radical balance and photooxidant formation in polluted environments, where the modeled $\mathrm{OH}$ is $30 \%$ larger with the revised rate coefficient.

\subsection{Potential Influence of Other Oxidants}

The essential assumption of our approach is that the $\mathrm{OH}$ radical is the most important oxidant for the compounds utilized in (1) and (2). Other potential oxidants are $\mathrm{O}_{3}, \mathrm{NO}_{3}$, and halogen atoms. For the VOCs in Figures 2 and 3 the $\mathrm{O}_{3}$ concentration of $50 \mathrm{ppb}$ corresponds to an equivalent $\mathrm{OH}$ concentration of $<50 \mathrm{~cm}^{-3}$. When assuming quasi steady state between production due to reaction of $\mathrm{NO}_{2}$ with $\mathrm{O}_{3}$ and degradation due to reaction with $\mathrm{NO}$, and by photolysis, an $\mathrm{NO}_{3}$ concentration of $4 \times 10^{6} \mathrm{~cm}^{-3}$ is calculated, which again corresponds to a very low equivalent $\mathrm{OH}$ concentration of $<300$ $\mathrm{cm}^{-3}$.

The rate coefficients for most of the VOCs utilized in Figures 2 and 3 with $\mathrm{Cl}$ or $\mathrm{Br}$ are not known. However, even with fairly large rate coefficients $\left(10^{-10} \mathrm{~cm}^{3} \mathrm{~s}^{-1}\right.$ for $\mathrm{Cl}$ [Atkinson and Aschmann, 1985] and $10^{-14} \mathrm{~cm}^{3} \mathrm{~s}^{-1}$ for $\mathrm{Br}$ [Bierbach et al., 1996]), Cl- and Br-atom concentrations of $>10^{5} \mathrm{~cm}^{-3}$ and $>10^{9} \mathrm{~cm}^{-3}$ would be required in order to compete with $\mathrm{OH}$ at Schauinsland. These concentrations are larger than the highest concentrations derived from VOC degradation during spring in the arctic planetary boundary layer (PBL) [Jobson et al., 1994; Solberg et al., 1996; Ramacher, 1997]. Cl concentrations in the marine boundary layer were estimated to be $<5 \times 10^{3}$ $\mathrm{cm}^{-3}$ [Singh et al., 1996; Rudolph et al., 1997]. On the basis of the available evidence and barring unexpected urban sources of halogen atoms, it is thus unlikely that the VOC-derived $\mathrm{OH}$ concentration is significantly influenced by other oxidants.

The situation is similar for $\mathrm{NO}_{x}$. Reactions of $\mathrm{NO}_{2}$ with $\mathrm{O}_{3}$ and $\mathrm{NO}_{3}$ do not lead to $\mathrm{NO}_{x}$ losses because of the photolysis of $\mathrm{NO}_{3}$ and the thermal decomposition of $\mathrm{N}_{2} \mathrm{O}_{5}$. Losses of $\mathrm{NO}_{x}$ due to formation of peroxyacetyl nitrate (PAN) are rather small since the mixing ratio of PAN at Schauinsland increased only slightly from the background concentration of 0.6 to $1 \mathrm{ppb}$ at $1130 \mathrm{LT}$ [Pätz et al., this issue]. As pointed out above, however, dry deposition, which is assumed to be of minor importance for the VOCs, cannot be neglected for $\mathrm{NO}_{x}$. 


\subsection{Budget of $\mathrm{OH}$ and $\mathrm{HO}_{\boldsymbol{x}}$}

Table 5 summarizes the budget of $\mathrm{OH}$ and $\mathrm{HO}_{x}$ radicals on the basis of the measurements. The concentrations of the reactants (e.g., $\mathrm{NO}_{2}, \mathrm{CO}$, and VOCs) were averaged over the results obtained at Kappel (0950 LT) and Schauinsland (1150 LT). The VOC concentrations from different instruments were assimilated as for the model calculations. Methane was included with a mixing ratio of $1.7 \mathrm{ppm}$. The rate coefficient for the reaction of $\mathrm{NO}_{2}$ with $\mathrm{OH}$ was adopted from Donahue et al. [1997].

The total accountable $\mathrm{OH}$ losses sum up to $72 \times 10^{6} \mathrm{~cm}^{-3}$ $\mathrm{s}^{-1}$; reaction with VOCs represents the major fraction $(60 \%)$. The $\mathrm{OH}$ production rate due to photolysis of $\mathrm{O}_{3}$, as calculated frum the measured $J_{O 1 D}$ and water vapor concentiation, is $5 \times$ $10^{6} \mathrm{~cm}^{-3} \mathrm{~s}^{-1}$. This source balances only a small fraction (7\%) of the total loss rate. A similar average production rate could be provided by the photolysis of HONO, if an upper limit of $5 \%$ of $\mathrm{NO}_{x}$ is assumed for the initial HONO mixing ratio. As stated above, the largest contribution of HONO photolysis to $\mathrm{OH}$ production is during the first $10 \mathrm{~min}$ of transport. During this time it could balance up to $60 \%$ of the total OH loss and hence could well serve as the starter of the photochemical system. When adopting a typical peroxide mixing ratio of $1 \mathrm{ppb}$ in the background air as measured earlier at Schauinsland in the early morning and late afternoon [Gilge et al., 1994; Kramp and Volz-Thomas, 1997], photolysis of $\mathrm{H}_{2} \mathrm{O}_{2}$ and organic peroxides should contribute $2 \times 10^{6} \mathrm{~cm}^{-3} \mathrm{~s}^{-1}$ to $\mathrm{OH}$ production.

Only the reaction of $\mathrm{OH}$ with $\mathrm{NO}_{2}$ constitutes a loss of $\mathrm{HO}_{x}$, whereas reactions of $\mathrm{OH}$ with $\mathrm{CO}$ and VOCs circulate $\mathrm{OH}$ to $\mathrm{HO}_{2}$. Thus the primary sources potentially balance up to $70 \%$ of the $\mathrm{HO}_{x}$ losses. As was noted by Kramp and Volz-Thomas [1997], the ozonolysis of alkenes represents another potentially important source of $\mathrm{OH}$ and $\mathrm{HO}_{2}$ [e.g., Paulson and Orlando, 1996] that had not been included in the budget for 1992 . Although some doubts had been raised about the mechanism [Scháfer et al., 1997], the production of $\mathrm{OH}$ and $\mathrm{HO}_{2}$ is now

Table 5. Budget of $\mathrm{OH}$ and $\mathrm{HO}_{x}$ Between Kappel and Schauinsland

\begin{tabular}{lcc}
\hline \multicolumn{1}{c}{ Process } & $\begin{array}{r}d[\mathrm{OH}] / d t, \\
10^{6} \mathrm{~cm}^{-3} \mathrm{~s}^{-1}\end{array}$ & $\begin{array}{c}d\left[\mathrm{HO}_{x}\right] / d t, \\
10^{6} \mathrm{~cm}^{-3} \mathrm{~s}^{-1}\end{array}$ \\
\hline $\mathrm{NO}_{2}+\mathrm{OH} \rightarrow \mathrm{HNO}_{3}$ & $-17^{\mathrm{a}}$ & $-17^{\mathrm{a}}$ \\
$\mathrm{CO}+\mathrm{OH}+\mathrm{O}_{2} \rightarrow \mathrm{HO}_{2}$ & $-12^{\mathrm{a}}$ & $\pm \mathbf{0}$ \\
$\mathrm{VOC}+\mathrm{OH} \rightarrow \mathrm{RO}_{2} \cdots \rightarrow \mathrm{HO}_{2}$ & $-43^{\mathrm{a}}$ & $+3^{\mathrm{b}}$ \\
$\mathrm{HO}_{2}+\mathrm{NO} \rightarrow \mathrm{OH}+\mathrm{NO}_{2}$ & $+59^{\mathrm{b}}$ & \pm 0 \\
$\left.\mathrm{O}^{1} D\right)+\mathrm{H}_{2} \mathrm{O} \rightarrow 2 \mathrm{OH}$ & $+5^{\mathrm{a}}$ & $+5^{\mathrm{a}}$ \\
$\mathrm{H}_{2} \mathrm{O}_{2}+h \nu \rightarrow 2 \mathrm{OH}$ & $+2^{\mathrm{c}}$ & $+2^{\mathrm{c}}$ \\
$\mathrm{HONO}+h \nu \rightarrow \mathrm{OH}+\mathrm{NO}$ & $+5^{\mathrm{d}}$ & $+5^{\mathrm{d}}$ \\
$\mathrm{R}-\mathrm{C}=\mathrm{C}-\mathrm{R}^{\prime}+\mathrm{O}_{3} \rightarrow \mathrm{OH}+$ & $+1^{\mathrm{a}}$ & $+2^{\mathrm{a}}$ \\
$\mathrm{HO}$ & & \\
Gross & 72 & 17 \\
$\quad \mathrm{Net}$ & $\pm 0^{\mathrm{e}}$ & $\pm 0^{\mathrm{e}}$ \\
\hline
\end{tabular}

[OH]: $7 \times 10^{6} \mathrm{~cm}^{-3}$; [HONO]: $1.1 \mathrm{ppb}\left(5 \%\right.$ of $\left.\mathrm{NO}_{x}\right) ; J(\mathrm{HONO}):$ $1.6 \times 10^{-3} \mathrm{~s}^{-1} ; \mathrm{CH}_{4}: 1.7 \mathrm{ppm} ;\left[\mathrm{NO}_{x}\right]_{t 1}: 29 \mathrm{ppb} ;\left[\mathrm{NO}_{x}\right]_{t 2}: 3.7 \mathrm{ppb}$; $k_{\mathrm{NO2,OH}}: 9 \times 10^{-12} \mathrm{~cm}^{3} \mathrm{~s}^{-1}$ [Donahue et al., 1997]; [NO $]_{\ell 1, t 2}: 18 / 3$ $\mathrm{ppb} ;[\mathrm{CO}]_{t 1}: 386 \mathrm{ppb} ;[\mathrm{CO}]_{t 2}: 256 \mathrm{ppb} ; k_{\mathrm{CO}, \mathrm{OH}}: 2.1 \times 10^{-13} \mathrm{~cm}^{3} \mathrm{~s}^{-1}$ [Atkinson et al., 1997]; [O $\left.]_{3}\right]_{11}: 37 \mathrm{ppb} ;\left[\mathrm{O}_{3}\right]_{t 2}: 53 \mathrm{ppb} ;\left[\mathrm{H}_{2} \mathrm{O}\right]: 3 \times 10^{17}$ $\mathrm{cm}^{-3}$; M: $2.46 \times 10^{19} \mathrm{~cm}^{-3}$ for Kappel and $2.25 \times 10^{19} \mathrm{~cm}^{-3}$ for Schauinsland.

${ }^{\text {a }}$ Derived from measurements.

'Inferred to close budget (required amplification factor: 1.1).

'Estimated from measurements made during SLOPE92.

${ }^{\mathrm{d}}$ Upper limit due to assumed HONO concentration.

${ }^{c}$ Quasi steady state assumption. confirmed by spectroscopic measurements [Donahue et al., 1998; Mihelcic et al., 1999]. The $\mathrm{HO}_{x}$ yield from the ozonolysis of olefins ranges from $60 \%$ for the ozonolysis of ethene [Mihelcic et al., 1999] to $106 \%$ for the ozonolysis of 3-carene [Atkinson et al., 1992].

The average reactivity of the measured alkenes toward $\mathrm{O}_{3}$ $\left(\Sigma\left[\mathrm{VOC}_{i}\right] k_{\mathrm{O} 3}\right)$ at Kappel in the morning and at Schauinsland at noontime was $2 \times 10^{-6} \mathrm{~s}^{-1}$. Assuming a $\mathrm{HO}_{x}$ yield of $100 \%$ for the ozonolysis of all measured olefinic compounds, the resulting $\mathrm{OH}$ production rate could be as large as $2 \times 10^{6} \mathrm{~cm}^{-3}$ $\mathrm{s}^{-1}$, that is, $40 \%$ of the primary $\mathrm{OH}$ production by photolysis of ozone. When including this radical source, approximately $90 \%$ of the $\mathrm{HO}_{x}$ losses can be balanced, and the hypothetical amplification factor required to close the budget is 1.1 . It is defined by (5), where $L_{\mathrm{NO} 2}$ and $\Sigma L_{\mathrm{VOC}}$ are the rates at which $\mathrm{OH}$ radicals react with $\mathrm{NO}_{2}$ and VOCs and $P_{p r}$ is the total primary production rate of $\mathrm{HO}_{x}$.

$$
\varphi=\frac{L_{\mathrm{NO}_{2}}+\Sigma L_{\mathrm{VOC}}-P_{P r}}{\Sigma L_{\mathrm{VOC}}}
$$

The intrinsic radical amplification potential of the VOC oxidation mechanism in the presence of high $\mathrm{NO}_{x}$ concentrations is the photolysis of the carbonyl compounds that are formed in the reaction of $\mathrm{RO}$ with $\mathrm{O}_{2}$. Photolysis of formaldehyde ( $\mathrm{HCHO}$ ) leads to the formation of $\mathrm{H}$-atoms and $\mathrm{HCO}$-radicals (branching ratio 30-45\% [Moortgat et al., 1980; Rodgers, 1990]), which are immediately converted to $\mathrm{HO}_{2}$ by reaction with $\mathrm{O}_{2}$, thus providing a total $\mathrm{HO}_{x}$ yield of $60-90 \%$. Photolysis of higher carbonyl compounds can lead to fragmentation yielding shorter alkyl peroxy radicals [Atkinson, 1995], which are then converted to $\mathrm{HO}_{2}$ by reaction with $\mathrm{NO}$.

During SLOPE96, formaldehyde (HCHO) was measured at Kappel and at Schauinsland using tunable diode laser spectroscopy and a commercial monitor based upon the Hantzsch reaction [Pätz et al., this issue]. In addition, a large number of carbonyl compounds were identified and quantified at both sites in samples that were analyzed by high-performance liquid chromatography (HPLC) [Pätz et al., this issue] and by GC/MS (B. Kolahgar et al., unpublished manuscript, 1999). The latter included compounds up to $C_{10}$, partially of biogenic origin. The total amount of carbon confined in the identified carbonyl compounds was approximately $20 \mathrm{ppb} \mathrm{C}$.

The photolysis rates of the $C_{1}-C_{4}$ compounds were calculated following the method described by Jenkin et al. [1997]. The photolysis rate of hexanal $\left(5 \times 10^{-5} \mathrm{~s}^{-1}\right)$ was calculated by Heiden [1998] from unpublished data. This value was adopted for all $>C_{6}$ aldehydes. For $>C_{6}$ ketones the photolysis rate of propanone was adopted as an upper limit. When adopting the radical yield of $\mathrm{HCHO}$ for all measured carbonyl compounds, the photolysis of these compounds would contribute to $\mathrm{HO}_{x}$ production at a rate of $1.5-2.5 \times 10^{6} \mathrm{~cm}^{-3} \mathrm{~s}^{-1}$ and would then indeed put the $\mathrm{HO}_{x}$ budget into balance. The large uncertainty is due to the fact that the HCHO concentration at Schauinsland could be overestimated by as much as a factor of 2 [Patz et al., this issue], besides the large errors in the estimated photolysis rates and quantum yields for the higher carbonyl compounds. It should be noted, however, that photolysis of HCHO made by far the largest contribution $(\sim 70 \%)$.

In conclusion, when considering all the possible processes of radical production and recreation, it seems possible to close the $\mathrm{HO}_{x}$ budget for $[\mathrm{OH}]=7 \times 10^{6} \mathrm{~cm}^{3}$ within the error margins arising from the uncertainties in the rate coefficients and in the measurements. The latter include uncertainties in 
the calibration and in the representatives of the measurements. In particular, measurements of carbonyl compounds and alkenes were only made at the surface sites. Because of the relatively short chemical lifetime of some of these compounds, the surface data may overestimate their overall contribution to the radical budget. A more detailed analysis can only be accomplished with a high-resolution three-dimensional model that is capable of treating the transport and dispersion in the valley and includes a rather detailed chemical scheme. The first step in this direction is described by Fiedler et al. [this issue], who demonstrate the capability of the Karlsruhe Atmospheric Mesoscale Model (KAMM) to describe the transport and dispersion of the tracer in the valley.

The budget for the 1992 experiment required an amplification factor (equation (5)) of almost 2 for an $\mathrm{OH}$ concentration of $7 \times 10^{6} \mathrm{~cm}^{-3}$ at an average $\mathrm{NO}_{x}$ level of $40 \mathrm{ppb}$ [Kramp and Volz-Thomas, 1997]. With the revised rate coefficient for the reaction of $\mathrm{NO}_{2}$ with $\mathrm{OH}$ [Donahue et al., 1997], the amplification factor decreases to 1.5 , and inclusion of $\mathrm{HO}_{x}$ production from $\mathrm{H}_{2} \mathrm{O}_{2}$ photolysis and smaller carbonyl compounds would bring the factor down to 1.4 , still significantly larger than the amplification factor determined from the budget for SLOPE96. Judging from the data collected in SLOPE96, it is unlikely that the missing biogenic VOCs (photolysis of carbonyl compounds, ozonolysis of biogenic alkenes, and increased recycling of $\mathrm{OH}$ ) would sufficiently reduce the amplification factor because of the much higher $\mathrm{NO}_{x}$ concentrations in 1992. Therefore the possibility remains that the methodology produces too high $[\mathrm{OH}]$, even in a rather ideal setup. Alternatively the results suggest that there are fundamental problems with our understanding of $\mathrm{HO}_{\boldsymbol{x}}$ chemistry in the high-NO${ }_{x}$ regime. The easiest way to close the $\mathrm{HO}_{x}$ budget would be by assuming a lower value for the rate coefficient for $\mathrm{NO}_{2}+\mathrm{OH}$. As is noted by Donahue et al. [1997] and Dransfield et al. [1999], the value at STP has a large uncertainty, and the data shown by Donahue et al. [1997] would indeed extrapolate to a lower value of approximately $7 \times 10^{-11} \mathrm{~cm}^{-3} \mathrm{~s}^{-1}$ at 300 $\mathrm{K}$ and $1 \mathrm{~atm}$.

\section{Conclusions}

A time-averaged $\mathrm{OH}$ concentration of $(7-10) \times 10^{6} \mathrm{~cm}^{-3}$ was estimated in a quasi-Lagrangian experiment from the decay of $\mathrm{NO}_{x}$ and selected VOCs in the city plume of Freiburg during transport to Schauinsland. The ideal nature of the site and the comprehensive set of measurements made during SLOPE96 gives a relatively high level of confidence in the estimated $\mathrm{OH}$ concentration. The meteorological situation during SLOPE96 was not as favorable as in 1992, when the first experiment was conducted with much less supporting measurements. However, the results of SLOPE96 largely confirm the assumptions made in the analysis of the 1992 campaign. The relatively large $\mathrm{OH}$ concentrations derived from the two campaigns in the presence of high $\mathrm{NO}_{x}$ mixing ratios are in reasonable agreement with results from other studies, when the prevailing conditions and the dependence of $[\mathrm{OH}]$ on the $\mathrm{NO}_{2}$ mixing ratio is taken into account.

Calculations made with a slightly revised version of RADM2 give approximately 2 times lower $\mathrm{OH}$ concentrations. Possible reasons are the underestimation of radical production by ozonolysis or incomplete treatment of the chemistry of the higher VOCs and an even lower value for the rate coefficient for $\mathrm{NO}_{2}+\mathrm{OH}$. While these possibilities remain to be investigated in detailed modeling studies, our results provide experimental evidence that currently used photochemical models may tend to underestimate the $\mathrm{OH}$ concentration in the high- $\mathrm{NO}_{x}$ regime. It is interesting to note in this context that Satsumabayashi et al. [1992] found extremely high $\mathrm{OH}$ concentrations $\left(20 \times 10^{6} \mathrm{~cm}^{-3}\right)$ in an extremely polluted air mass $(50 \mathrm{ppb}$ $\mathrm{NO}_{x}$ ) over Japan. Since the rate of ozone formation is closely linked to $[\mathrm{OH}]$, our finding would also suggest that ozone predictions made on the basis of such model simulations tend to underestimate the rate at which ozone and other photooxidants are formed in the high- $\mathrm{NO}_{x}$ regime, that is, in the outflow of pollution sources. Future work will include an assessment of the approach of VOC-derived OH concentrations by comparison with direct measurements during an experiment made in 1998 in the plume of Berlin.

Acknowledgments. The authors are grateful to Sabine Jansen and Heiner Geiß for support with the model simulations. We very much enjoyed the stimulating discussions in the SLOPE community. Thanks are also due to Franz Rohrer for providing details on the $\mathrm{OH}$ and $\mathrm{NO}_{2}$ concentrations of the POPCORN campaign and to Neil Donahue for helpful comments on the reaction of $\mathrm{NO}_{2}$ with $\mathrm{OH}$. The conduction of the SLOPE campaign was supported by the German Minister for Research (BMBF) as part of the former EUROTRAC subproject TOR (grant 07 EU $7235 \mathrm{~A}$ ), and the interpretation was partly sponsored under the German Tropospheric Research Focus (TFS, LT3, grant 422-4007 07TFS31/HA.3).

\section{References}

Atkinson, R., Gas-phase tropospheric chemistry of organic compounds, J. Phys. Chem. Ref. Data Monogr., 2, 1-216, 1994.

Atkinson, R., Gas-phase tropospheric chemistry of organic compounds, in Volatile Organic Compounds in the Atmosphere, edited by R. E. Hester and R. M. Harrison, pp. 1-140, R. Soc. of Chem., Cambridge, England, 1995.

Atkinson, R., Gas-phase tropospheric chemistry of volatile organic compounds, 1, Alkanes and alkenes, J. Phys. Chem. Ref. Data, Monogr., 2, 215-290, 1997.

Atkinson, R., and S. M. Aschmann, Kinetics of the gas-phase reactions of $\mathrm{Cl}$ atoms with chloroethenes at $296 \pm 2 \mathrm{~K}$ and atmospheric pressure, Int. J. Chem. Kinet., 17, 33-41, 1985.

Atkinson, R., S. M. Aschmann, J. Arey, and B. Shorees, Formation of $\mathrm{OH}$ radicals in the gas-phase reactions of $\mathrm{O}_{3}$ with a series of terpenes, J. Geophys. Res., 97, 6065-6073, 1992.

Atkinson, R., D. L. Baulch, R. A. Cox, R. F. Hampson Jr., J. A. Kerr, M. J. Rossi, and J. Troe, Evaluated kinetic photochemical and heterogeneous data for atmospheric chemistry: Supplement V, J. Phys. Chem. Ref. Data, 26, 521-1011, 1997.

Bierbach, A., I. Barnes, and K. H. Becker, Rate coefficients for the gas-phase reactions of bromine radicals with a series of alkenes, dienes, and aromatic hydrocarbons at $298 \pm 2 \mathrm{~K}$, Int. J. Chem. Kinet., 28, 565-577, 1996.

Blake, N. J., S. A. Penkett, K. C. Clemitshaw, P. Anwyl, P. Lightman, A. R. W. Marsh, and G. Butcher, Estimates of atmospheric hydroxyl radical concentrations from the observed decay of many reactive hydrocarbons in well-defined urban plumes, J. Geophys. Res., 98, 2851-2864, 1993.

Bohn, B., and C. Zetsch, Rate constants of $\mathrm{HO}_{2}+\mathrm{NO}$ covering atmospheric conditions, $1, \mathrm{HO}_{2}$ formed by $\mathrm{OH}+\mathrm{H}_{2} \mathrm{O}_{2}, J$. Phys. Chem., 101, 1488-1493, 1997.

Brandenburger, U., T. Brauers, H.-P. Dorn, M. Hausmann, and D. H. Ehhalt, In-situ measurements of tropospheric hydroxyl radicals by folded long-path laser absorption during the field campaign POPCORN in 1994, J. Atmos. Chem., 31, 181-204, 1998.

Calvert, J. G., Hydrocarbon involvement in photochemical smog formation in Los Angeles atmosphere, Environ. Sci. Technol., 10, 256262, 1976.

Donahue, N. M., M. K. Dubey, R. Mohrschladt, L. D. Kenneth, and J. G. Anderson, High-pressure flow study of the reactions $\mathrm{OH}+$ $\mathrm{NO}_{x} \rightarrow \mathrm{HONO}_{x}$, J. Geophys. Res., 102, 6159-6168, 1997.

Donahue, N. M., J. H. Kroll, J. G. Anderson, and K. L. Demerjian, 
Direct observation of $\mathrm{OH}$ production from the ozonolysis of olefins, Geophys. Res. Lett., 25, 59-62, 1998.

Dransfield, T. J., K. K. Perkins, N. M. Donahue, J. G. Anderson, M. M. Sprengnether, and K. L. Demerjian, Temperature- and pressuredependent kinetics of the gas-phase reaction of the hydroxyl radical with nitrogen dioxide, Geophys. Res. Lett., 26, 687-690, 1999.

Ehhalt, D. H., F. Rohrer, A. Wahner, M. J. Prather, and D. R. Blake, On the use of hydrocarbons for the determination of tropospheric OH concentrations, J. Geophys. Res., 103, 18,981-18,997, 1998.

Eisele, F. L., G. H. Mount, F. C. Fehsenfeld, J. Harder, E. Marovich, D. D. Parrish, J. R. Roberts, M. Trainer, and D. Tanner, Intercomparison of tropospheric $\mathrm{OH}$ and ancillary trace gas measurements at Fritz Peak Observatory, Colorado, J. Geophys. Res., 99, 18,60518,626, 1994.

Eisele, F. L., G. H. Mount, D. Tanner, A. Jefferson, R. Shetter, J. W. Harder, and E. J. Williams, Understanding the production and interconversion of the hydroxyl radical during the Tropospheric $\mathrm{OH}$ Photochemistry Experiment, J. Geophys. Res., 102, 6457-6465, 1997.

Fiedler, F., I. Bischoff-Gauß, N. Kalthoff, and G. Adrian, Modeling of the transport and diffusion of a tracer in the Freiburg-Schauinsland area, J. Geophys. Res., this issue.

Flocke, F., A. Volz-Thomas, H. J. Buers, W. Patz, H. J. Garthe, and D. Kley, Long-term measurements of alkyl nitrates in southern Germany, 1 , General behavior and seasonal and diurnal variation, $J$. Geophys. Res., 103, 5729-5746, 1998.

Geller, L. S., J. W. Elkins, J. M. Lobert, A. D. Clarke, D. F. Hurst, J. H. Butler, and R. C. Myers, Tropospheric $\mathrm{SF}_{6}$ : Observed latitudinal distribution and trends, derived emissions, and interhemispheric exchange time, Geophys. Res. Lett., 24, 6705-6708, 1997.

Gilge, S., D. Kley, A. Volz-Thomas, and H. Geiß, Messungen von Wasserstoffperoxid und organischen Hydroperoxiden am Schauinsland im Schwarzwald, Ein Beitrag zur Charakterisierung der limitierenden Faktoren bei der Ozonproduktion, Ber. Forsch. Julich Jül2998, Forsch. Julich, Jülich, Germany, 1994.

Hameed, S., J. P. Pinto, and R. W. Stewart, Sensitivity of the predicted $\mathrm{CO}-\mathrm{OH}-\mathrm{CH}_{4}$ perturbation to tropospheric $\mathrm{NO}_{x}$ concentrations, $J$. Geophys. Res., 84, 763-768, 1979.

Harrison, R. M., J. D. Peak, and G. M. Collins, Tropospheric cycle of nitrous acid, J. Geophys. Res., 101, 14,429-14,439, 1996.

Hatakeyama, S., K. Izumi, T. Fukuyama, H. Akimoto, and N. Washida, Reactions of $\mathrm{OH}$ with $\alpha$-pinene and $\beta$-pinene in air: Estimate of global CO production from atmospheric oxidation of terpenes, $J$. Geophys. Res., 96, 947-958, 1991.

Heiden, A. C., Einfluß verschiedener Streßfaktoren auf die Emission pflanzlıcher fluchtiger organischer Verbindungen, Ph.D. thesis, Gerhard-Mercator-Univ.-GH Duisburg, Germany, 1998.

Holland, F., U. Aschmutat, M. HeBling, A. Hofzumahaus, and D. H. Ehhalt, Highly time resolved measurements of $\mathrm{OH}$ during POPCORN using laser-induced fluorescence spectroscopy, J. Atmos. Chem., 31, 205-225, 1998.

Jenkın, M. E., S. M. Saunders, and M. J. Pilling, The tropospheric degradation of volatile organic compounds: A protocol for mechanism development, Atmos. Environ., 31, 81-104, 1997.

Jobson, B. T., H. Niki, Y. Yokouchi, J. Bottenheim, F. Hopper, and R. Leaitsch, Measurements of $C_{2}-C_{6}$ hydrocarbons during the Polar Sunrise Experiment: Evidence for $\mathrm{Cl}$ atom and $\mathrm{Br}$ atom chemistry, J. Geophys. Res., 99, 25,355-25,368, 1994.

Kalthoff, N., V. Horlacher, U. Corsmeier, A. Volz-Thomas, B. Kolahgar, H. Geiß, M. Möllmann-Coers, and A. Knaps, Influence of valley winds on transport and dispersion of airborne pollutants in the Freiburg-Schauinsland area, J. Geophys. Res., this issue.

Kessler, C., and U. Platt, Nitrous acid in polluted air masses-Source and formation pathways, paper presented at 3rd Symposium on the Physico-Chemical Behavior of Atmospheric Pollutants, Eur. Comm., Varese, Italy, 1984.

Kley, D., J. Beck, P. I. Grennfelt, $\emptyset$. Hov, and S. A. Penkett, Tropospheric Ozone Research (TOR)-A sub-project of EUROTRAC, $J$. Atmos. Chem., 28, 1-9, 1997.

Kohlmann, J. P., H. Bluhm, and D. Poppe, Influence of updated gas-phase rate constants on modeled tropospheric OH concentrations, Atmos. Environ., in press, 1999.

Kramp, F., and A. Volz-Thomas, On the budget of $\mathrm{OH}$ radicals and ozone in an urban plume from the decay of $C_{5}-C_{8}$ hydrocarbons and $\mathrm{NO}_{x}$, J. Atmos. Chem., 28, 263-282, 1997.

Leighton, P. A., Photochemistry of Alr Pollution, Academic, San Diego, Calif., 1961.
Logan, J. A., M. J. Prather, S. C. Wofsy, and M. B. McElroy, Tropospheric chemistry: A global perspective, J. Geophys. Res., 86, 7210$7254,1981$.

Marston, G., C. D. McGill, and A. R. Rickard, Hydroxyl-radical formation in the gas-phase ozonolysis of 2-methylbut-2-ene, Geophys. Res. Lett., 25, 2177-2180, 1998.

McKeen, S. A., and S. C. Liu, Hydrocarbon ratios and photochemical history of air masses, Geophys. Res. Lett., 20, 2363-2366, 1993.

McKeen, S. A., S. C. Liu, E.-Y. Hsie, X. Lin, J. D. Bradshaw, S. Smyth, G. L. Gregory, and D. R. Blake, Hydrocarbon ratios during PEMWEST A: A model perspective, J. Geophys. Res., 101, 2087-2109, 1996.

McKenna, D. S., Analytic solutions of reaction diffusion equations and implications for the concept of an air parcel, J. Geophys. Res., 102, $13,719-13,725,1997$.

McKenna, D. S., C. J. Hord, and J. M. Kent, Hydroxyl radical concentrations and Kuwait Oil fire emission rates for March 1991, J. Geophys. Res., 100, 26,005-26,025, 1995.

Mihelcic, D., M. Heitlinger, D. Kley, P. Müsgen, and A. Volz-Thomas, Formation of hydroxyl and hydroperoxy radicals in the gas-phase ozonolysis of ethene, Chem. Phys. Lett., 301, 559-564, 1999.

Moortgat, G. K., W. Klippel, K. H. Mobus, W. Seiler, and P. Warneck, Laboratory measurements of photolytic parameters for formaldehyde, $F A A-E E-80-47$, Off. of Environ. and Energy, Fed. Aviat. Admin., Washington, D. C., 1980.

Mount, G. H., and E. J. Williams, An overview of the Tropospheric OH Photochemistry Experiment, Fritz Peak/Ihado Hill, Colorado, fall 1993, J. Geophys. Res., 102, 6171-6186, 1997.

Mount, G. H., F. L. Eisele, D. J. Tanner, J. W. Brault, P. V. Johnston, J. W. Harder, E. J. Williams, A. Fried, and R. Shetter, An intercomparison of spectroscopic laser long-path and ion-assisted in situ measurements of hydroxyl concentrations during the Tropospheric OH Photochemistry Experiment, fall 1993, J. Geophys. Res., 102, 6437-6455, 1997.

Munger, J. W., S. C. Wofsy, P. S. Bakwin, S.-M. Fan, M. L. Goulden, B. C. Daube, A. H. Goldstein, K. E. Moore, and D. R. Fitzjarrald, Atmospheric deposition of reactive nitrogen oxides and ozone in a temperate deciduous forest and subarctic woodland, 1, Measurements and mechanisms, J. Geophys. Res., 101, 12,639-12,657, 1996.

Niki, H., P. D. Maker, C. M. Savage, L. P. Breitenbach, and M. D. Hurley, FTIR spectroscopic study of the mechanısm for the gasphase reaction between ozone and tetramethylethylene, J. Phys. Chem., 91, 941-946, 1987.

Patz, H.-W., et al., Measurements of trace gases and photolysis frequencies during SLOPE96 and a course estimate of the local OH concentration from $\mathrm{HNO}_{3}$ formation, J. Geophys. Res., this issue.

Paulson, S. E., and J. J. Orlando, The reactions of ozone with alkenes: An important source of $\mathrm{HO}_{x}$ in the boundary layer, Geophys. Res. Lett., 23, 3727-3730, 1996.

Paulson, S. E., M. Chung, A. D. Sen, and G. Orzechowska, Measurement of $\mathrm{OH}$ radical formation from the reaction of ozone with several biogenic alkenes, J. Geophys. Res., 103, 25,533-25,539, 1998.

Platt, U., M. Rateike, W. Junkermann, J. Rudolf, and D. H. Ehhalt, New tropospheric OH measurements, J. Geophys. Res., 93, 51595166, 1988.

Ramacher, B., Messung organischer Spurengase in der arktischen Troposphäre: Hinweise auf einen regionalen halogeninduzierten Ozonabbau, Ber. Forsch. Juilich Jul-3424, Forsch. Juilich, Julich, Germany, 1997.

Roberts, J. M., F. C. Fehsenfeld, S. C. Liu, M. J. Bollinger, C. Hahn, D. L. Albritton, and R. E. Sievers, Measurements of aromatic hydrocarbon ratios and $\mathrm{NO}_{x}$ concentrations in the rural troposphere: Observation of air mass photochemical aging and $\mathrm{NO}_{x}$ removal, Atmos. Environ., 18, 2421-2432, 1984.

Rogers, J. D., Ultraviolet absorption cross sections and atmospheric photodissociation rate constants of formaldehyde, J. Phys. Chem., 94, 4011-4015, 1990.

Rohrer, F., D. Brüning, E. S. Grobler, M. Weber, D. H. Ehhalt, R. Neubert, W. Schüßler, and I. Levin, During the field campaign POPCORN in 1994, J. Atmos. Chem., 31, 119-137, 1998.

Rudolph, J., and F. J. Johnen, Measurements of light atmospheric hydrocarbons over the Atlantic in regions of low biological activity, J. Geophys. Res., 95, 20,583-20,591, 1990.

Rudolph, J., B. Ramacher, C. Plass-Dülmer, K.-P. Müller, and R. Koppmann, The indirect determination of chlorine atom concentra- 
tion in the troposphere from changes in the patterns of nonmethane hydrocarbons, Ser. Tellus, B, 49, 592-601, 1997.

Satsumabayashi, H., H. Kurita, Y.-S. Chang, G. R. Carmichael, and H. Ueda, Diurnal variation of $\mathrm{OH}$ radical and hydrocarbons in a polluted air mass during long-range transport in central Japan, Atmos. Environ., Part A, 26, 2835-2844, 1992.

Schäfer, C., O. Horie, J. N. Crowley, and G. K. Moortgat, Is the hydroxyl radical formed in the gas-phase ozonolysis of alkenes?, Geophys. Res. Lett., 24, 1611-1614, 1997.

Schmitt, R., and A. Volz-Thomas, Climatology of ozone, PAN, CO, and NMHC in free troposphere over southern Atlantic, J. Atmos. Chem., 28, 245-262, 1997.

Singh, H. B., J. R. Martinez, D. G. Hendry, R. J. Jaffe, and W. B. Johnson, Assessment of the oxidant-forming potential of light saturated hydrocarbons in the atmosphere, Environ. Sci. Technol., 15, $113-119,1981$.

Singh, H. B., A. N. Takur, Y. E. Chen, and M. Kanakidou, Tetrachloroethylene as an indicator of low $\mathrm{Cl}$ atom concentrations in the troposphere, Geophys. Res. Lett., 23, 1529-1532, 1996.

Solberg, S., N. Schmidbauer, A. Semb, F. Stordal, and $\emptyset$. Hov, Bound- ary layer ozone depletion as seen in the Norwegian Arctic, J. Atmos. Chem., 23, 301-332, 1996.

Stockwell, W. R., and D. Kley, The EURO-RADM mechanism: A gas-phase chemical mechanism for European air quality studies, Ber. Forsch. Jülich Jül-2868, Forsch. Jülich, Jülich, Germany, 1994.

Stockwell, W. R., P. Middleton, J. S. Chang, and X. Tang, The Second Generation Regional Acid Deposition Model chemical mechanism for regional air quality modeling, J. Geophys. Res., 95, 16,343-16,367, 1990.

Volz-Thomas, A., H. Geiß, and N. Kalthoff, The Schauinsland Ozone Precursor Experiment (SLOPE96): Scientific background and main results, J. Geophys. Res., this issue.

B. Kolahgar and A. Volz-Thomas (corresponding author), Institut für Chemie der Belasteten Atmosphäre (ICG-2), Forschungszentrum Jülich GmbH, Leo-Brandt-Straße, D-52425 Jülich, Germany. (a.volzthomas@fz-juelich.de)

(Received April 12, 1999; revised October 6, 1999; accepted October 13, 1999.) 